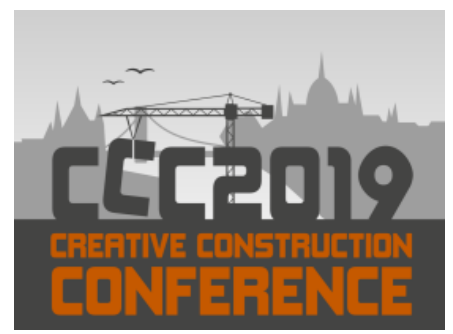

Available online at 2019.creative-construction-conference.com/proceedings/

CCC 2019

Proceedings of the Creative Construction Conference (2019) 020

Edited by: Miroslaw J. Skibniewski \& Miklos Hajdu

https://doi.org/10.3311/CCC2019-020

Creative Construction Conference 2019, CCC 2019, 29 June - 2 July 2019, Budapest, Hungary

\title{
The Delunay Triangulation in the design of architectural gridshells
}

\author{
Anna Stefańska*, Ewelina Gawell, Wiesław Rokicki \\ ${ }^{a}$ Department of Structure Design, Construction and Technical Infrastructure, \\ Faculty of Architecture, Warsaw University of Technology, Poland
}

\begin{abstract}
The design of original gridshell forms has become an increasingly complex process, which aims to search for unique spatial systems which are also effective engineering solutions - both architecturally as well as structurally. The search for synergistic solutions which combine the aesthetics of the form with structural logic is supported by modern bionic tendencies. They allow the reproduction of the organic shapes not only by means of proportions, but also by mimicking the biological developmental processes and by understanding the logic of the structural forms occurring in nature. The analogies between architectural design and morphogenesis of biological forms have increased the interest in bionic structures as a whole. The improvement of digital tools based on algorithmic codes has enabled architects to implement their bold designs based on the logic of Nature's technologies.

One of the most interesting bionic methods of discretization of structural surfaces is Delaunay triangulation, a dual graph of the Voronoi Diagram, which describes the divisions of the plane and space found in nature. Examples can be found in the patterns of a dragonfly wing, giraffe's mottled skin or a turtle's shell. The Delaunay divisions are more and more often used in the design of architectural forms based on gridshells. Solutions for such systems are obtained through generative modeling, and the algorithm responsible for the surface discretization is incorporated into 3D modeling programs. A big advantage of using digital generators in the search for optimal architectural and structural solutions is the ability to model multiple-variants and to the easily modify them (the models result from iterations of the entered numerical data).

The paper will present the trends in the development of spatial bionic gridshells based on Delaunay triangulation, as well as the results from own research on selected gridshells. The undertaken analyses compare material efficiency on two analyzed cases.
\end{abstract}

(C) 2019 The Authors. Published by Budapest University of Technology and Economics \& Diamond Congress Ltd. Peer-review under responsibility of the scientific committee of the Creative Construction Conference 2019.

Keywords: Surface discretization, generative modeling, Delunay

\section{Introduction}

Increasingly complex structural forms are a characteristic feature of modern architectural design. The original, bionic shapes of the 21 st century buildings are created as a result of the creative search, but also the changing philosophy in architectural design - surprising in terms of plasticity, technical and technological rationality. Computational calculation methods lead to the improvement of modeling tools as well as the fabrication of building elements and even whole objects. Currently, architects can design spatial forms with very complex structures. Algorithmization of

*Corresponding author: Author email: anna.stefanska2@pw.edu.pl 
Anna Stefańska, et al. / Proceedings of the Creative Construction Conference (2019) 020 https://doi.org/10.3311/CCC2019-020

the supporting design tools provides new opportunities, but also creates new challenges, including rationalization, which necessitates a greater focus on conceptual modeling in the design process. The article analyzes open roofs that are small scale architectural objects with a relatively uncomplicated function. The design of structural forms in relation to the contemporary computing tools and the known mathematical models is increasingly more important. The interdisciplinary design of gridshells leads to sophisticated structural systems, which are more and more often characterized by unobvious, complex shapes, with their geometries referring to free fractal structures, sometimes going beyond the paradigms of Euclidean geometry[1]. In the search for the new architectural gridshell solutions bionic patterns play an important role. With the development of research tools we gain the knowledge about the formation of the surface structures of living organisms. The knowledge becomes an inspiration in the design of load-bearing structures and also in the broadly understood civil engineering and materials science.

\section{Optimisation in architectural and structural designing}

Optimization is an important element in the design of modern technical architectural structures. In the context of creative designs and exploration, at the intersection of architecture and structure, form finding and topology deserve special attention. To paraphrase Confucius, the American mathematician Andre Cherkaev compares optimization to: "searching for a black cat in a dark room in a minimal time"- assuming that the search range corresponds to a room filled with furniture. This sentence was originally written down by Confucius and it read: ,, The hardest thing of all is to find a black cat in a dark room, especially if there is no cat in it". To find the cat, however, minimal lighting is needed. There is no golden ratio, and the skillful use of possible variants is most important - this is optimization according to A. Cherkaev. With regard to architecture, optimization should be understood as the process of rationalizing technical solutions by undertaking solutions which are the most beneficial at the early design stage. The more advanced the building process is, the more expensive the building optimization is. In search for savings in contemporary architecture, an increasingly frequent phenomenon is a multivariate concept deepened by thorough analysis carried out on several levels - these include structural analysis (structural optimization), energy, urban planning, materials, etc. All these elements have an impact on the form - its technical and technological efficiency and artistic expression. Yet another development can be observed in the parameterization of elements involved in the design of the form which allows to iterate the design process which lead to the "emergence" of the field of effective solutions. Regardless of the chosen technique, achieving the intended goal requires a well-thought-out sequence of actions and the use of the right tools at the right time. Optimal form finding with the use of parametric tools requires "algorithmic thinking"'[2].

To optimize the structural forms, the form needs to be determined along with the rational cross-sections of the elements, which is related to the choice of appropriate materials. The rational design choices and following the systems of forces have the greatest influence on the aesthetics of form. In this context, the following issues deserve special attention: design of the form and discretization of structural surfaces. One of the more interesting directions of exploration are topologies describing structural deformations[1], which can lead to rational solutions. A more famous example of the use of topology in architecture is the catenary curve described in the Renaissance (the first sketches of suspended chains can be found in the works of Leonardo da Vinci). The Simon Stevin manual from 1634 states that the rope hanging freely between supports is shaped parabolically. At the same time, Christian Huygens described the geometry of the catenary curve (Latin Catena - chain), proving that the curve, similar in its shape to a parabola, is an independent creation. In the last century, Antonio Gaudi, whose work on chain models lasted 10 years, was the architect who contributed most to the development of the research on catenary curves. Among others, the physical model of the Sagrada Familia in 1:10 scale was created at that time.

One of the more important issues in the optimal design of structural forms is the discretization of the surface. The selection of the appropriate method of division, as well as the indication of the mesh density has a fundamental impact on the efficiency of the structure 
Anna Stefańska, et al. / Proceedings of the Creative Construction Conference (2019) 020 https://doi.org/10.3311/CCC2019-020

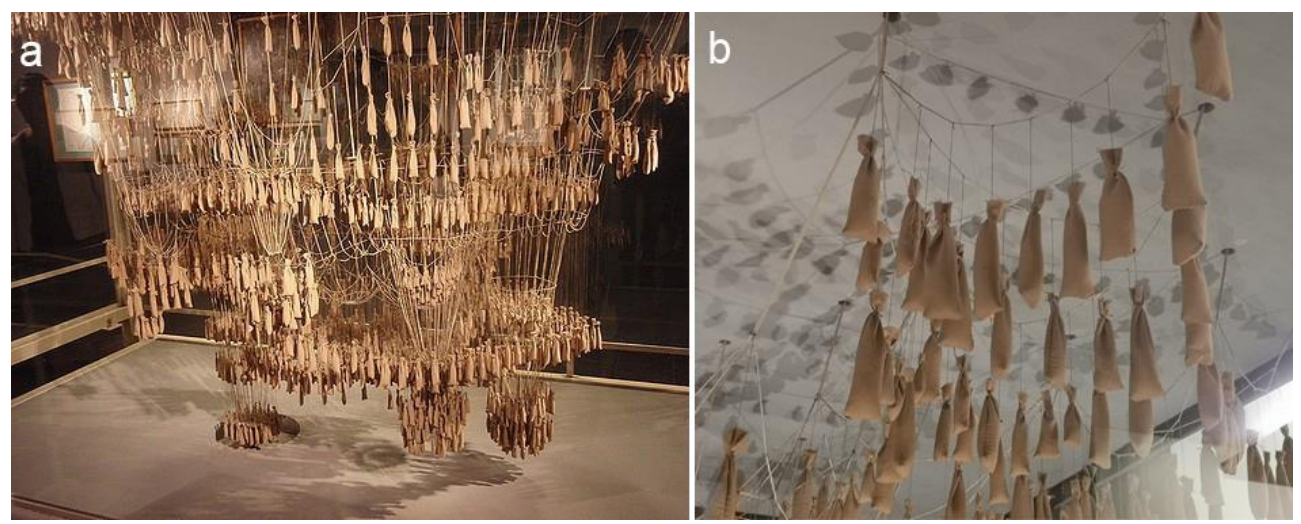

Fig. 1. A. Gaudi - model research; (a) 1:10 model of Sagrada Familia; ( $b$ ) detail of the binding of the weights;

Apart from the Finite Elements Method, which leads to effective structural solutions, many other methods are still used to discretize contemporary surfaces. One of them is Delaunay's Triangulation, which uses the bionic pattern of the Voronoi Diagram - being its dual graph. An accessible tool for delineating Delaunay divisions is the Grasshopper plugin for Rhino program, which allows the discretization of the surface based on the adopted geometric parameters. However, the modeled gridshell must then be subjected to structural analysis - this requires the cooperation between two different programs. In addition, the model determined on the basis of the geometry and intuitive assumptions is subjected to further optimizations. It can be done with Dynamic Relaxation - an additional function of the Gasshopper plug-in. It is a numerical method of computational modeling, the aim of which is to find such a geometry that all forces are in equilibrium. This can lead to rationalization of solutions, including reduction of the total weight of the structure, which has a direct impact on the reduction of the amount of material used and reduction of later construction costs. This method makes topological transformations of a given structure, leading to relaxation of nodes.

Referring to selected mathematical models and methods of optimization of structural surfaces, the effect of relaxation of the nodes on the structure of the roofing was examined. The examples of structures that were created thanks to the Grasshopper plug-in for Rhino program and the Kangaroo2 plug-in for Grasshopper (this plug-in allows simulation of gravitational forces on the structure, thanks to which it is possible to create catenary models), were then analyzed structurally using Robot Structural Analysis programs.

Access to computer aided design tools significantly accelerated the search for the optimal structural form. An example of such a tool is the Grasshopper-Karagaroo2 plug-in used in the following tests, which assigned loads imitating physical forces to the pre-created mesh. The ability to change the working force, the extensibility of the elements and the placement of the supports, generate a system of solutions that have been subjected to structural analysis in the next phase. The study compares the grids generated by means of dynamic relaxation with the grids projected onto the created geometry. The results of the gridshell analysis described below were built on these basic assumptions (Fig. 2).

The structure is a roofing (open roof) on a square plan with a total area of $900.0 \mathrm{~m}^{2}$;

- the roofing is based on three supports, determined using the Voronoi formula(in the Grasshopper plug-in for Rhino). The supports are positioned in such a way that they form a triangle similar to an equilateral one, and at the same time they are centers of fields with an area of $300.0 \mathrm{~m}^{2}$ each. Static support scheme - articulated joints;

- Delaunay triangulation was used to determine the structural divisions of the surface, assuming that the maximum beam length was $4.5 \mathrm{~m}$.

Two analyses of the effectiveness of particular geometries of forms(examination of the effect of the deflection deflection of the structure) and the metric of bar division (maximum length of bars: $3.0 \mathrm{~m}, 3.5 \mathrm{~m}, 4.0 \mathrm{~m}, 4.5 \mathrm{~m}, 5.0 \mathrm{~m}$ ) were carried out on the example of Delunay meshes dropped on a chain model or relaxed on a chain model. 
Anna Stefańska, et al. / Proceedings of the Creative Construction Conference (2019) 020 https://doi.org/10.3311/CCC2019-020

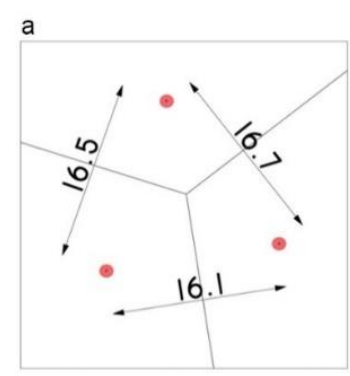

b

C

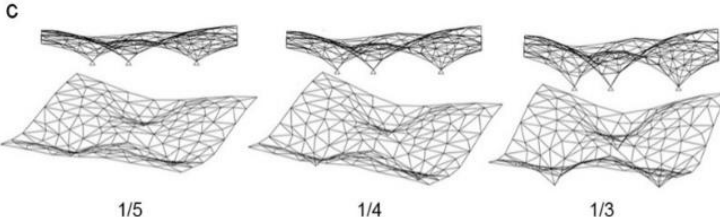

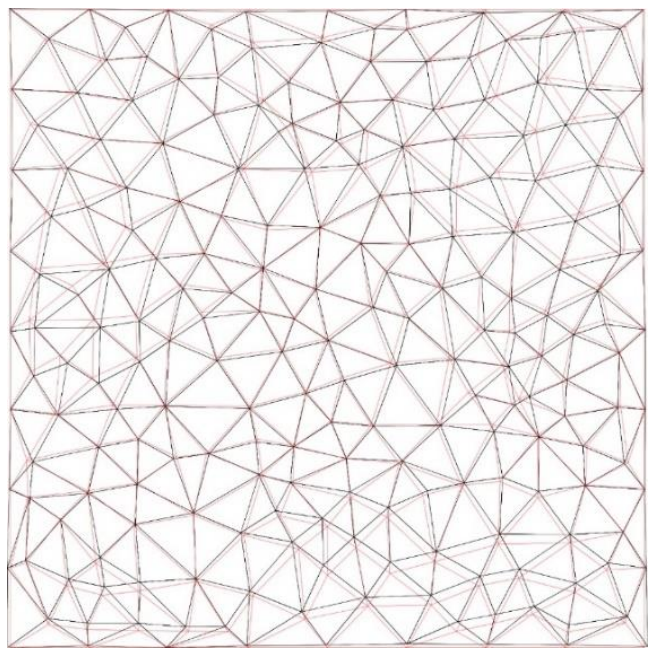

Fig. 2.(a) scheme of supports location and determining the Voronoi polygons of a comparable surface; (b) Diagram of Delaunay divisions with the maximum $4.5 \mathrm{~m}$ long beams; (c)the curvature heights; (d) illustration of overlapping variants $\mathrm{C}$ from Analysis 1 and Analysis 2 (the $1 / 3$ ratio), showing the degree of changes in the geometry of Delaunay divisions (red) due to topological transformations using the logic of chain models (black)

\subsection{Analysis 1}

The Delunay triangulation, initially applied to a flat geometry, was then projected onto the displaced geometry (node points were only moved in the $\mathrm{Z}$ axis so that they were on the surface of the curvature) determined according to the catenary model principles:

- the deflection is determined by the height of the middle point to the average support span ratio. The following three options have been proposed depending on the height of the center point (Fig.2.):

Variant A1 - height to the support span ratio: 1/5

Variant B1 - height to the support span ratio: 1/4

Variant $\mathrm{C} 1$ - height to the support span ratio: $1 / 3$

Uniform closed THEX (hexagonal tubes), TRON (round tubes) and TREC (rectangular tubes) profiles made of S355 steel were adopted for all the layouts. One of the assumptions was the homogeneity of the structure, hence for each of the variants one of the most effective external dimension of the profile was selected (regardless of the fact that individual beams in the structure do not work equally). At the same time, it was possible to change the wall thickness of a given profile - though from the outside the profiles should look the same. Due to the same starting geometry of all variants, a maximum deformation value of $19.5 \mathrm{~cm}$ was assumed. In the search for effectiveness, the minimum mass criterion for the entire roof was adopted. Due to the variable roof area (caused by the change of the deflection), the weight per $1.0 \mathrm{~m}^{2}$ of the roof was also considered as an important parameter.

Two profiles differing in wall thickness were selected for all variants. The most effective variant, based on the adopted weight criterion was Variant C1 (total weight of $73253 \mathrm{~kg}$ ). Although this variant was characterized by the largest area of the roofing, it was characterized by the smallest weight per $1.0 \mathrm{~m}^{2}$ of the roof, which amounted to $72.38 \mathrm{~kg} /$ $\mathrm{m}^{2}$ - about $30 \%$ less than the most unfavorable option. Additionally, in all the analyzed variants, the TRON (round) steel profile was the most effective. 
Anna Stefańska, et al. / Proceedings of the Creative Construction Conference (2019) 020 https://doi.org/10.3311/CCC2019-020

Table 1. Results of analyzed structures where rods were projected on a geometry with a maximum projected length of rods of $4.5 \mathrm{~m}$

\begin{tabular}{|c|c|c|c|c|c|c|}
\hline $\begin{array}{l}\text { The } \\
\text { curvature } \\
\text { height to the } \\
\text { support span } \\
\text { ratio }\end{array}$ & $\begin{array}{l}\text { Adapted } \\
\text { profile(type } \\
\text { and } \\
\text { dimensions } \\
\text { in } \mathrm{mm} \text { ) }\end{array}$ & $\begin{array}{l}\text { Maximum } \\
\text { deformation } \\
{[\mathrm{cm}]}\end{array}$ & $\begin{array}{l}\text { Total } \\
\text { length } \\
\text { of the } \\
\text { rods } \\
{[\mathrm{m}]}\end{array}$ & $\begin{array}{l}\text { Total } \\
\text { weight } \\
{[\mathrm{kg}]}\end{array}$ & $\begin{array}{l}\text { Surface } \\
\text { area } \\
{\left[\mathrm{m}^{2}\right]}\end{array}$ & $\begin{array}{l}\text { Weight per } \\
m^{2} \text { of the } \\
\text { surface } \\
{\left[\mathrm{kg} / \mathrm{m}^{2}\right]}\end{array}$ \\
\hline $1 / 3$ & $\begin{array}{l}\text { TRON } \\
406 \times 8,0 \\
406 \times 6,3\end{array}$ & 18,4 & 1536,09 & 97337 & 943,75 & 103,13 \\
\hline $1 / 4$ & $\begin{array}{l}\text { TRON } \\
355 \times 6,3 \\
355 \times 8,0\end{array}$ & 19 & 1558,42 & 92454 & 965,17 & 95,79 \\
\hline $1 / 5$ & $\begin{array}{l}\text { TRON } \\
323 \times 5,6 \\
323 \times 6,3\end{array}$ & 19,4 & 1593,86 & 73253 & 1012,01 & 72,38 \\
\hline
\end{tabular}

\subsection{Analysis 2}

Analysis 2 adopts a similar geometry for the gridshell form. Nodal points have been released. Subjecting the mesh to dynamic relaxation resulted in the nodal points being able to move not only in the $\mathrm{Z}$ axis, but in accordance with the acting forces. Thanks to the freed the nodes the structure could better adapt to the given loads(Fig.2d).

Through the generative algorithm, the adopted variants change the geometrical layout to a small degree - changes are unnoticeable in the scale of the entire gridshell. As the constructional analysis shows, the change in the structural layout has significantly improved the results. Analysis 2 adopts variants analogous to Analysis 1 with the same center point height to the support span ratio:

Variant A2 - height to the support span ratio: 1/5

Variant B2 - height to the support span ratio: $1 / 4$

Variant C2 - height to the support span ratio: 1/3

Similarly to Analysis 1, homogeneous closed profiles were adopted by selecting from the THEX (hexagonal tubes), TRON (round tubes) and TREC (rectangular tubes) profiles made of S355 steel. In this case, for all the variants, the round tube also proved to be the most effective. Variant $\mathrm{C} 2$ (with the 1/3 ratio) reached the smallest total mass (analogously as in Analysis 1) equal to $54094 \mathrm{~kg}$. The mass ratio calculated per $1.0 \mathrm{~m}^{2}$ of the roof was $53.46 \mathrm{~kg} / 1.0 \mathrm{~m}^{2}$, which is almost a $40 \%$ better result than the worst version in this analysis.

Table 1. Results of analyzed of catenary relaxed structures with a maximum projected length of rods of $4.5 \mathrm{~m}$.

\begin{tabular}{lllllll}
\hline $\begin{array}{l}\text { The } \\
\text { curvature } \\
\text { height to the } \\
\text { support span } \\
\text { ratio }\end{array}$ & $\begin{array}{l}\text { Adapted } \\
\text { profile(type } \\
\text { and } \\
\text { dimensions } \\
\text { in mm) }\end{array}$ & $\begin{array}{l}\text { Maximum } \\
\text { deformation } \\
{[\mathrm{cm}]}\end{array}$ & $\begin{array}{l}\text { Total } \\
\text { length } \\
\text { of the } \\
\text { rods } \\
{[\mathrm{m}]}\end{array}$ & $\begin{array}{l}\text { Total } \\
\text { weight } \\
{[\mathrm{kg}]}\end{array}$ & $\begin{array}{l}\text { Surface } \\
\text { area } \\
{\left[\mathrm{m}^{2}\right]}\end{array}$ & $\begin{array}{l}\text { Weight per } \\
\mathrm{m}^{2} \text { of the } \\
\text { surface } \\
{\left[\mathrm{kg} / \mathrm{m}^{2}\right]}\end{array}$ \\
\hline & $\begin{array}{l}\text { TRON } \\
335 \times 8\end{array}$ & 16,1 & 1531,06 & 83974 & 945,73 & 88,76 \\
& $\begin{array}{l}335 \times 6,3 \\
\text { TRON }\end{array}$ & & & & & \\
$1 / 3$ & $\begin{array}{l}323 \times 6,3 \\
323 \times 5,6\end{array}$ & 16,4 & 1548,05 & 68413 & 968,64 & 70,68 \\
& & & & & & \\
$1 / 5$ & $\begin{array}{l}\text { TRON } \\
273 \times 6,3\end{array}$ & 16,6 & 1581,37 & 54094 & 1011,95 & 53,46 \\
& $273 \times 5,0$ & & & & & \\
\hline
\end{tabular}


Anna Stefańska, et al. / Proceedings of the Creative Construction Conference (2019) 020

https://doi.org/10.3311/CCC2019-020

\subsection{Comparison of results}

In Analysis 2, there is a significant improvement in the efficiency of structures in relation to the layouts in Analysis 1. There is also a visible relationship between Analysis 1 and Analysis 2, where all the results of A2, B2, $\mathrm{C} 2$ are much more favorable.

Variant A: weight improvement: the A2 variant is 13,390 kg lighter than the A1 variant, which results in $13.76 \%$ lower material consumption;

Variant B: weight improvement: the B2 variant is $24,041 \mathrm{~kg}$ lighter than variant B1, which results in $26.00 \%$ lower material consumption;

Variant C: weight improvement: the C2 variant is $19159 \mathrm{~kg}$ lighter than variant $\mathrm{C} 1$, which results in $26.15 \%$ lower material consumption;

It should also be noted that the $\mathrm{C}$ variants in each of the analyzes achieve the smallest total weight, despite the largest length of beams.

\section{Conclusion}

The inspiration of bionics in contemporary architecture and civil engineering is an interesting phenomenon. The use of mathematical models mapping the morphology of living organisms may lead to the rationalization of technical solutions when it is justified and implied by structural logic. An example of such are the analyses carried out in the above study - where the use of the catenary model was dictated by the model of physical forces acting on the designed structure. The conducted analyses also confirmed that modifying the form "exerts" a great influence on the structural efficiency. For this reason, the pursuit of shape optimization should be carried out at an early stage of creating the architectural concept. The aesthetic evaluation of structural forms is subjective. However, in designing of the spatial form through morphological analysis, one can find an increased share of logic in the creation of a work of art - assuming that what is functional, rational, etc. is also beautiful. However, can the ethos of creative freedom in architectural design be enclosed in the definition of rationalism?

Quo Vadis Architectura? Will the search for beauty lead to rationalism? Or perhaps logical thinking is the starting point for the creation of perfect works? Regardless of the answer, it should be stated that the search for beauty of the structural forms does not always lead to logical solutions. On the other hand, the search for logical solutions can lead to bionic systems whose beauty results from the beauty of Nature.

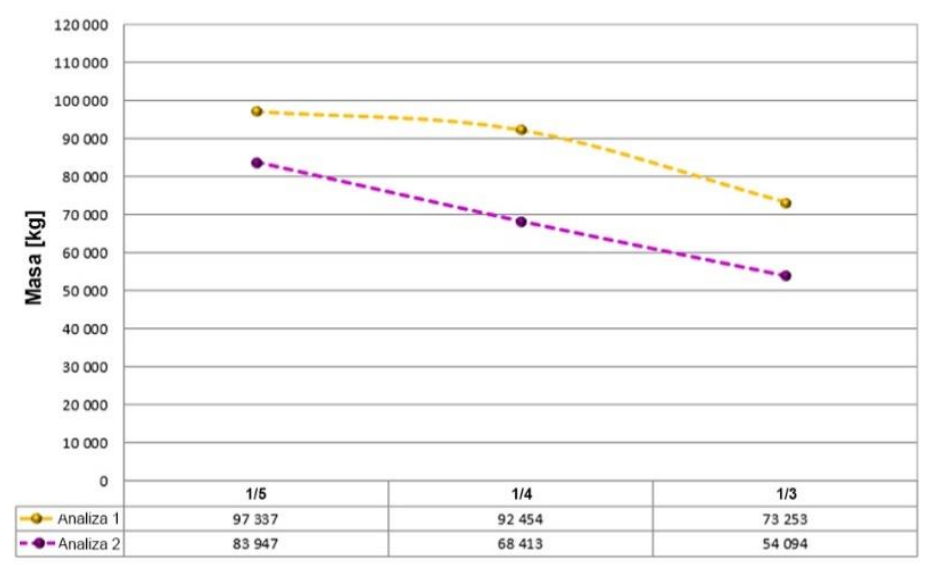

Fig. 5. List of results obtained from the analysis of individual variants from Analysis 1 and Analysis 2

Topological optimization of the structural surfaces using logic of catenary models allowed to reduce the consumption of structural material by $21.97 \%$ on average. 
Anna Stefańska, et al. / Proceedings of the Creative Construction Conference (2019) 020

https://doi.org/10.3311/CCC2019-020

\section{References}

[1]Gawell E., Synergia formy przestrzennej i statyki w optymalnym ksztaltowaniu struktur prętowych, PhD thesis, supervisor: Assoc. Prof. Eng. Wiesław Rokicki, Faculty of Architecture, Warsaw University of Technology, Warsaw, Poland 2015, p. 69:

[2]ARCHITECTURAE et ARTIBUS - 3/2016, Projektowanie parametryczne oraz parametryczne narzędzia cyfrowe $w$ projektowaniu architektonicznym, Krystyna Januszkiewicz, Zachodniopomorski Uniwersytet Technologiczny w Szczecinie, 2016:

"Parametric design is defined here as a process based on algorithmic thinking, which allows the expression of parameters and principles which define, code and explain the relationships between the design intention and the design response. This process is justified in architectural design when there is such a relationship between the elements of the project, which requires manipulation of information about the complex geometry of the form and its structure. Parametric design is not a new concept and has always been a part of architectural design."

[3] Davis D., The MacLeamy curve, "Daniel Davis - blog”,15.10.2011, [acces: 03.01.2019] < http://www.danieldavis.com/macleamy/ >

[4] Qingpeng Li, ,,Form follows force, a theoretical framework for Structural Morphology, and Form-Finding research on shell structures”- PhD thesis, TU Delft, 2018

[5] Picon A., "Digital Culture in Architecture - an introduction for the design proffesions", Publishing House: Birkhauser Basel, Germany 2010, ISBN: 978-3-0346-0259-4

[6] Wang Michael Yu, Wang Xiaoming, Guo Dongming, “A level set method form structural topology optimization”" Computer Methods in Applied Mechanics and Engineering" 192, 2003, [accessed on 05 December 2018]

< https://pdfs.semanticscholar.org/7d23/f522cf17ac3de97d6f16fa8f616d716fb383.pdf > 